\title{
Measurements of natural deposition ice nuclei in Córdoba, Argentina
}

\author{
M. L. López and E. E. Ávila \\ FaMAF, Universidad Nacional de Córdoba, IFEG-CONICET, Córdoba, Argentina \\ Correspondence to: E. E. Ávila (avila@famaf.unc.edu.ar) \\ Received: 6 November 2012 - Published in Atmos. Chem. Phys. Discuss.: 11 December 2012 \\ Revised: 21 February 2013 - Accepted: 1 March 2013 - Published: 15 March 2013
}

\begin{abstract}
Ice nucleation in the atmosphere is of practical and fundamental importance since ice crystals influence the release of snow, rain and hail. Suspended aerosols in the atmosphere typically initiate freezing at temperatures below $-15^{\circ} \mathrm{C}$; although occasionally freezing occurs at higher temperatures. In this work we describe an experimental device designed to measure the concentration of natural ice nuclei under controlled temperature and supersaturation conditions. The measurements were performed at Córdoba City, for temperatures between $-15^{\circ} \mathrm{C}$ and $-30^{\circ} \mathrm{C}$ and the sampled air was supersaturated with respect to ice and subsaturated with respect to liquid water; under these conditions the deposition ice nuclei were quantified. There are few studies reported in the literature regarding measurements of deposition ice nuclei concentration and, to our knowledge, there are no previous laboratory data of this kind of ice nuclei for $T<-20^{\circ} \mathrm{C}$. The results show that the number of deposition ice nuclei increases at colder temperatures and higher supersaturations. These results are in general in good agreement with results previously reported by other authors. A fitting function which depends on temperature and supersaturation is proposed to parameterize the results obtained in the present work.
\end{abstract}

\section{Introduction}

Ice formation is one of the main processes involved in the initiation of precipitation. Some aerosols serve to nucleate ice in clouds. They are called ice nuclei (IN) and they are generally solid particles, insoluble in water (Pruppacher and Klett, 1997). The function of the IN in the development of the precipitation is still poorly understood, and therefore it needs to be studied (Levin and Cotton, 2009).

Temperature and the supersaturation ratio with respect to ice $\left(S_{\mathrm{i}}\right)$ are the two main parameters which determine ice nucleation. At temperatures near $-40^{\circ} \mathrm{C}$ homogeneous freezing of supercooled droplets occurs while at temperatures warmer than about $-36^{\circ} \mathrm{C}$ the only means for initiation of the ice phase in the atmosphere involves a foreign insoluble material called an ice-forming nucleus (IN) (e.g. DeMott et al., 2011; Cantrell and Heymsfield, 2005). This process, called heterogeneous freezing, may occur at lower icesupersaturation ratios than homogeneous freezing because the specific surface properties of IN markedly reduce the $S_{\mathrm{i}}$ threshold for heterogeneous ice nucleation with respect to homogeneous freezing (Pruppacher and Klett, 1997). Since the supersaturation is rarely high enough for ice nucleation to occur homogeneously in the lower atmosphere, the number concentration of IN, temperature and supersaturation required to activate IN are considered as key information for the understanding of primary ice formation in clouds.

Heterogeneous nucleation involves several modes: condensation freezing (the cloud condensation nuclei, CCN, act as IN during the condensation process at temperatures below $0^{\circ} \mathrm{C}$ ); immersion freezing (particles immersed into the droplet act as IN at temperature below $0^{\circ} \mathrm{C}$ ); contact freezing (ice is formed by the collision of cloud droplets with interstitial aerosols within the cloud); deposition nucleation (ice deposits on the IN directly from the vapor phase, which means that the environment is supersaturated with respect to ice and can be subsaturated with respect to liquid water) (Vali, 1985). Although there are many ice nuclei measuring systems, none of them allow the quantification of IN concentration by all the nucleation mechanisms (Santachiara et al., 2010). 
Although the heterogeneous ice formation processes is not completely understood, several systems have been employed to study the IN behavior. They mainly consist in (a) in-situ and laboratory measurements, (b) empirical parameterizations and (c) numerical models. With respect to the first one, different techniques have been developed to measure and characterize IN during the last $50 \mathrm{yr}$. Aircraft have been used to measure ice crystal concentrations and to relate them with IN concentration (Hobbs and Rangno, 1985). These measurements have revealed that, in a cloud, the former can be higher than the latter by some orders of magnitude. It could be a consequence of the ice multiplication processes that include the breakup of primary ice particles (Hobbs and Farber, 1972) and ice splinter production during the freezing of droplets (Hallett and Mossop, 1974; Mossop, 1985). However, this technique does not reveal any information regarding the freezing mechanisms.

Regarding laboratory measurements, the most traditional and simple method involves a cloud chamber where a sample of air is rapidly cooled by sudden expansion. This expansion produces the condensation of water vapor on some of the airborne particles and leads to a cloud of supercooled droplets. Some of them will freeze and will grow into ice crystals, which are counted by the glitter in an illuminated volume of the cloud (Schaefer, 1948). Another similar technique that modifies the system of counting was developed by Bigg (1957). It uses a supersaturated sugar solution placed at the bottom of the cloud chamber. Thus, the ice crystals are counted on this solution when they fall and form a visible print. Different methods involve the drawing of large samples of air through a membrane filter that retain ice nuclei or collect aerosols (e.g. Santachiara et al., 2010). This technique allows estimate the IN concentration by counting the ice crystals that develop upon the exposure of the substrate to freezing temperatures and supersaturation. Also, it allows the processing of the collected aerosols in the laboratory. In the last years important results have been obtained from measurements in chambers of more complex design: the CFDC (Continuous Flow Diffusion Chamber) has provided many IN concentration data for various atmospheric environments and IN chemical compositions (e.g. DeMott et al., 2003); the AIDA (Aerosols Interaction and Dynamics in the Atmosphere) chamber have been used to investigate the heterogeneous ice nucleation of various dust samples (e.g. Möler et al., 2006); and the FINCH (Fast Ice Nuclei Chamber) has allowed to determine the concentration of IN for various types of aerosols at different supersaturation and temperature conditions (Bundke et al., 2008). A complete review of the last instruments used to measure ice nuclei can be found in DeMott et al. (2011).

Numerical models can be used to parameterize homogeneous freezing rates, but the process is more complex for the heterogeneous nucleation mechanism (Möler et al., 2006). This is the reason why the widely used parameterizations of IN rely on empirical relations for the concentrations of IN as functions of temperature and/or $S_{\mathrm{i}}$. Although the experimental studies report that, at a single temperature, IN number concentrations can be variable in more than 3 orders of magnitude for different locations and time periods (DeMott et al., 2011), there is a clear correlation with the temperature, whereby the number of active IN increases as the temperature of the cloud decreases. This exponential form of the dependence of IN on temperature has been shown by numerous authors (e.g. Fletcher, 1962; Hussain and Saunders, 1984; Meyers et al., 1992).

In recent years, advances in computational tools have put an increased emphasis on numerical modeling studies of clouds (DeMott et al., 2011), and predictions from new ice nucleation parameterizations have been applied in cloud parcel models (e.g. Eidhammer et al., 1995). However, they must always be validated by experimental studies. A review of the results from the last 60 years of laboratory experiments of heterogeneous ice nucleation has been compiled by Hoose and Möler (2012).

In most of the work reported, measurements have been made under conditions in which saturation $\left(S_{\mathrm{w}}\right)$ or supersaturation over water prevailed. In the simplest cases the supersaturation is achieved by differential control of a warmer ice plates. However, measurements in the regime below water saturation are critical to the study and understanding of the deposition nucleation (DeMott et al., 2011). In fact, it has been seen that $S_{\mathrm{i}}$ is a good parameter to characterize the deposition nucleation (Huffman, 1973) in observations of natural IN between $-12^{\circ} \mathrm{C}$ and $-20^{\circ} \mathrm{C}$. Phillips et al. (2008) presented the only empirical parameterizations which cover the full range of possible $S_{\mathrm{i}}$ and temperatures for deposition nucleation, completing those of Meyers et al. (1992). Many of the recent studies about deposition nucleation are focused in analyzing the characteristics of the aerosols acting as IN. Thus, Kulkarni et al. (2012) and Möler et al. (2006) have reported the activated fraction of different kind of dust particles at different sizes, $S_{\mathrm{i}}$ conditions and temperatures.

Although nearly $50 \mathrm{yr}$ have elapsed since the beginning of the study of ice nuclei, still no agreement has been reached as to the most appropriate technique to quantify the IN concentration (Santachiara et al., 2010). The role of supersaturation in the activation of the IN has been identified as the main factor producing the divergence among the results of IN quantification using different techniques. Besides, results show that the ice-nuclei content on the atmosphere varies considerably from day to day and from place to place. In short, the actual knowledge about IN is still incomplete (DeMott et al., 2011). Therefore, considering the role of IN in the initiation of ice phase and the subsequent effect on climate and the hydrological cycle, there is a need to improve the models describing the IN number concentrations and analyze the response of IN to changes in the ambient aerosols (DeMott et al., 2011). As part of that need, the objective of this work is to quantify the ice nuclei concentrations at ground level in Córdoba City, Argentina, under a supersaturated-atmosphere 
with respect to ice and subsaturated with respect to liquid water, contributing to the understanding of heterogeneous nucleation involving the deposition nucleation mode. As far as we know, this is among the first work to measure the concentration of deposition ice nuclei in the Southern Hemisphere.

\section{Experimental device and measurements}

IN measurements were conducted in Córdoba, the second largest city in Argentina (approximately 1.3 million inhabitants). It is a mediterranean city located in a semiarid region in the centre of the country at $31.4^{\circ} \mathrm{S}$ latitude and $64.18^{\circ} \mathrm{W}$ longitude, and $470 \mathrm{~m}$ a.s.l. Unlike other sites at the same latitude, it has a moderate template climate. The main factors determining this difference are the altitude, the protection of the hills surrounding the city, and the cold Pampero wind blowing from the SW from Antarctica (mainly in winter). The IN measurements were carried out between April and July 2012, during Autumn and Winter seasons. A description of the sources of aerosols in Córdoba can be found in López et al. (2011).

Ice nuclei concentrations were measured in a cloud chamber placed in a cold room of height $3 \mathrm{~m}$ and floor area $2.5 \times 2.5 \mathrm{~m}^{2}$, with temperature control down to $-35^{\circ} \mathrm{C}$. Since in-situ and remote sensing observations have shown that more than half the clouds at temperatures lower than $-15^{\circ} \mathrm{C}$ to $-20^{\circ} \mathrm{C}$ contain ice, while at higher temperatures clouds are more often purely liquid (Kanitz et al., 2011), in this work the operating temperature was varied between $-15^{\circ} \mathrm{C}$ and $-30^{\circ} \mathrm{C}$. Ice supersaturation was ranged between 2 and $20 \%$.

The cloud chamber consisted in a cubic acrylic box of 46 $\mathrm{L}$ in volume. Figure 1 shows the schematic view of the chamber. The box cover has three holes: one hole allows the introduction of the temperature-humidity probe meter while the two last holes connect the chamber with the outside through plastic tubes. The system was air tight and all the inner surfaces of the chamber and tubes were thoroughly coated with glycerol to avoid frost formation.

The principle for increasing the relative humidity $(\mathrm{RH})$ in the cloud chamber was based on the adiabatic isobaric mixing of two air masses with different temperatures and $\mathrm{RH}$ (Curry and Webster, 1999). Because of the nonlinearity of the Clausius-Clapeyron equation, this kind of mixing may result in an increase in RH. Thus, the relative humidity of the cloud chamber was raised by injecting controlled volumes of humid air. Humid air was forced to flow into the cloud chamber from the exterior (ambient temperature) by means of a pump located through one of the tubes connected to the acrylic box. The volumetric capacity of the pump was approximately $2 \mathrm{~L}$; the volume of air entered was estimated to be approximately constant during each injection. While this air was injected, the same volume of air was removed through another plastic tube connecting the box and the outside. The air injected into the chamber has the same aerosol concentration as the

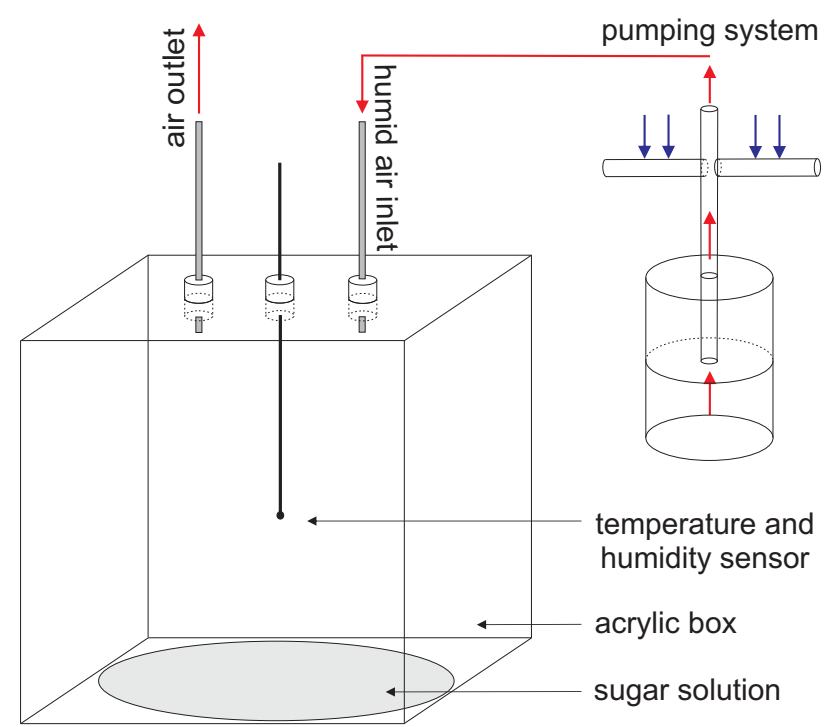

Fig. 1. General scheme of the cloud chamber.

air inside the chamber. Thus, this procedure ensures that the pressure and the number of aerosols are kept approximately constant inside the chamber.

The control of the increment in the RH as the air is successively injected allows the calibration of the system. Thus, knowing the increase of RH for each air injection, it is possible to estimate the increase produced by a known number of injections, even once the vapor saturation over ice $(\mathrm{RH}=100 \%)$ is exceeded. In order to determine the $\mathrm{RH}$ and temperature in the cloud chamber two different instruments were used: the EE31 Series Model D (E+E Elektronik) which has a remote sensing probe for $\mathrm{RH}$ measurements in the temperature range $[-40,180]^{\circ} \mathrm{C}$ and the Testo $435-4$ multifunction measuring instrument, which measures $\mathrm{RH}$ in the temperature range $[-50,150]^{\circ} \mathrm{C}$. Both instruments measure the $\mathrm{RH}$ over ice at temperatures below $0^{\circ} \mathrm{C}$ with resolution of $0.1 \% \mathrm{RH}$; under the same condition both instruments report the same RH within a resolution of $1 \%$.

As an example, Fig. 2 displays the time evolution of $\mathrm{RH}$ during successive air injections for one of the experiments carried out at $T=-21^{\circ} \mathrm{C}$. Initially $\mathrm{RH}<100 \%$ and it is increased with the air injections. Red arrows indicate the instant when each air injection was pumped into the box and it is very low in comparison to the total increment. The RH rising is measured during each injection and it is shown in Fig. 2. Note that the increments do not present a high dispersion (the average and standard deviation are 1.18 and 0.05 , respectively). The time until the maximum $\mathrm{RH}$ is achieved during each air injection is a consequence of the response of the humidity sensor. However, it must be considered that this maximum RH is achieved immediately after the end of the air injection. After each injection, the following one began when RH showed stability or a minimum decrease during the time. 


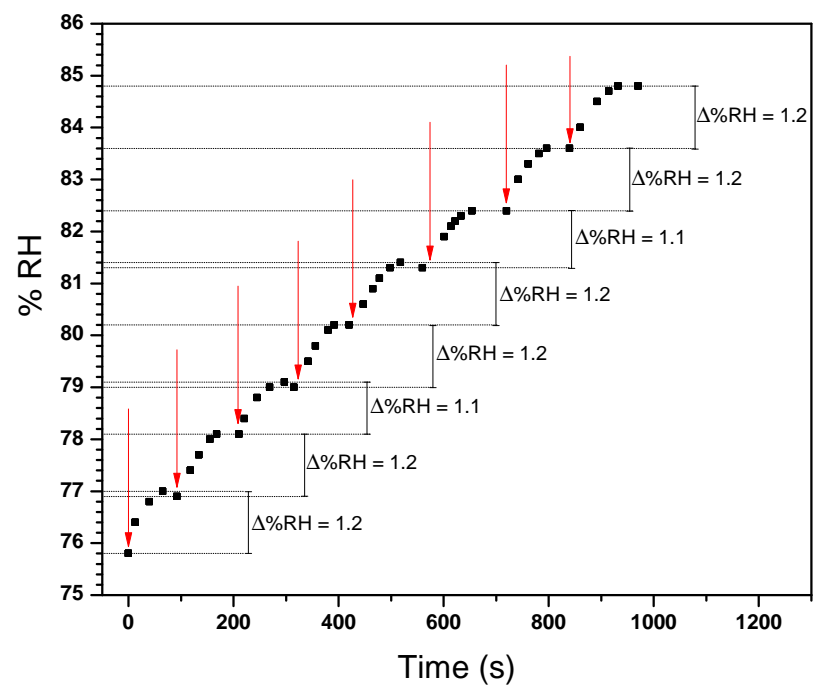

Fig. 2. Evolution of the relative humidity with time during the hot air inlet. Red arrows indicate the moment when air is injected.

The RH decrease is explained considering the difficulties in achieving an air-tight system. However, note that the loss in $\mathrm{RH}$ is not achieved until around 2 min after each injection and it is very low in comparison to the total increment.

The supersaturation condition is reached starting with $\mathrm{RH}$ slightly less than $100 \%$ in the cloud chamber and introducing the subsequent air injections from outside. The supersaturation value cannot be determined by the instruments but it is estimated by knowing the increase of RH for each air injection (calibration). An indicator that the supersaturation over ice is well determined from this method is given by the fact that no condensation takes place in the chamber until the supersaturation value predicted from the calibration is close to water saturation for the corresponding temperature. Supercooled cloud droplets are formed in the cloud chamber when the predicted supersaturation reaches the water saturation value.

Since the increase in humidity and supersaturation are achieved with the input of air at room temperature, the temperature of the cloud chamber was increased. Thus, when the measurements were carried out at $S_{\mathrm{i}}$ around $20 \%$, the increase of the temperature was $<4^{\circ} \mathrm{C}$. For each experiment, the difference in the temperature between the beginning and the end of the air injections was considered in the propagated errors. Thereby, the increase in temperature allowed measuring the IN concentration at $S_{\mathrm{i}}$ lower than around $20 \%$, but it was not the only factor limiting $S_{\mathrm{i}}$ conditions. The time until a particular $S_{\mathrm{i}}$ was reached also has to be considered. Although the air injections were quick, the number of air injections necessary to achieve $S_{\mathrm{i}}$ higher than $20 \%$ could contribute to the growth of ice nuclei. Thus, the IN activation stops enhancing the growth of the IN already activated. In addition to the increase in the temperature, this is the other reason why we have worked at $S_{\mathrm{i}}$ up to $20 \%$. Considering the experimental conditions which are involved in the measurement of $S_{\mathrm{i}}$ (variability in the RH increase during the injections, number of injections until reaching a particular $S_{\mathrm{i}}$, and accuracy of the RH sensor) an experimental uncertainty less than $2 \%$ for $S_{\mathrm{i}}$ was estimated for each experiment.

In order to quantify the number of ice particles produced in each experiment, a $34.5 \mathrm{~cm}$ diameter dish was placed on the floor of the cloud chamber. It contained a supercooled solution of cane sugar and water 3-mm thick. To avoid the freezing of this solution at low temperatures, the cryoscopic decrease was controlled with the addition of glycerol. The precautions recommended by Bigg (1957) and Castro et al. (1998) were followed. The main of them was the coating of the whole system (box and tubes) with glycerol to avoid frost formation on these surfaces. If the walls had not been covered with glycerol, the frost formed on the walls would have grown from the vapor supersaturated over ice, reducing the supersaturation and inhibiting the activation of ice nuclei. The supercooled sugar solution was frequently replaced since it absorbed some of the water during each experiment. This water absorption would have caused, at low temperatures, the freezing of the sugar solution, because is increasingly diluted throughout the experiments.

The activated IN grew at the expense of vapor until ice crystals were formed and these then fell down onto the sugar solution. Once there, these crystals could grow enough to be counted easily with a naked eye after a period of about three minutes, when they reach around $2 \mathrm{~mm}$ in diameter. Figure 3 shows the appearance of ice crystals on the sugar solution. Following this procedure at different conditions of temperature and $S_{\mathrm{i}}$, IN concentration was calculated as the ratio between the number of IN and the air volume contained over the dish. The error in the counting of ice crystals on the sugar solution was estimated in $10 \%$.

Each experiment was carried out following the same procedure which is described below. The cloud chamber and the internal walls of the plastic tubes were thoroughly coated with glycerol before each experiment, and placed inside the cold chamber at room temperature. The dish containing the sugar solution was placed inside the box. The box was placed uncovered to avoid the increase in RH during the temperature decrease. The box was covered after thermal equilibrium was reached. In these conditions, the air injections were begun and the temperature and RH sensor was continuously monitored. The calibration was completed when relative humidity in the box was close to $100 \%$ and the number of total injections to reach a particular $S_{\mathrm{i}}$ was determined. The sugar solution was controlled before all the injections had been carried out, to ensure no IN was activated before reaching supersaturation. Between experiments, the air in the cloud chamber was refreshed to decrease the RH below $100 \%$ and to renovate the IN. The glycerol covering was repeated on the box and the tubes. The dish was withdrawn from the cold chamber and allowed to return at room temperature to 


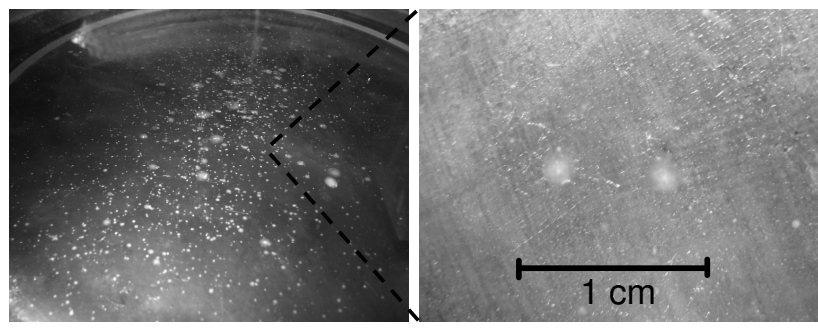

Fig. 3. Images of crystals grown on the sugar solution.

eliminate any grown crystals. The dish was placed into the cloud chamber when it reached room temperature. The temperature stabilization period was at least two hours between each experiment. The next experiment was begun when the thermal equilibrium had been reached.

The main advantage of this measuring system is that the IN can be activated and measured in times of the order of minutes, in contrast to other measurement methods which have times of the order of seconds. Besides, because the dish with the sugar solution is placed into the cloud chamber since the beginning of the experiment, all the activated IN are considered in the counting. Another key advantage of this new system over the standard two plates diffusion chamber is that much lower temperatures can be achieved in the cloud chamber. On another hand, this system allows the bulk of the aerosol sample to be subjected to a fairly uniform supersaturation and temperature, whereas the two plates diffusion chamber involves a range of supersaturations and temperatures across the chamber.

\section{Results and discussions}

The IN concentration was determined as a function of temperature and supersaturation, for the temperature range $[-15,-30]^{\circ} \mathrm{C}$ and supersaturation range $[2,20] \%$ over ice. The experiments were all performed for a supersaturatedatmosphere with respect to ice and subsaturated with respect to liquid water; then, only the deposition ice nuclei were quantified in the current work. Figure 4a shows a threedimensional plot representing IN concentration for different temperatures and supersaturations, while Fig. 4b shows, in color scale, the corresponding interpolated data. These graphics show an important variability of the results which is related to errors associated with the measurement technique (uncertainties in supersaturation, temperature and activated ice crystals counting) as well as to the inherent variability in the IN concentration. Nevertheless, the results clearly show that the number of deposition IN increases at colder temperatures and higher supersaturation.

In order to compare the present results with previously reported results, the data were grouped in three different ranges of supersaturation: the data with supersaturations between 2
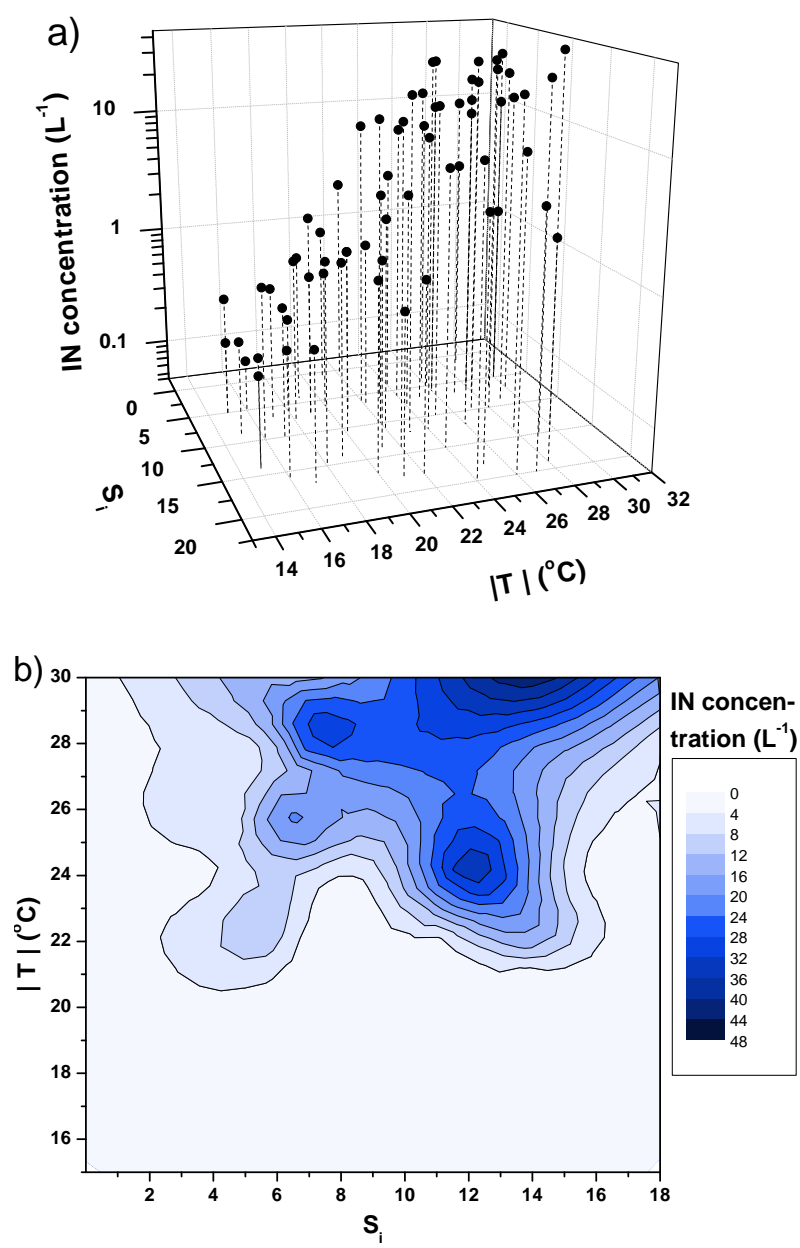

Fig. 4. (a) Three-dimensional plot representing IN concentration for different temperatures and supersaturations, (b) the corresponding interpolated data in color scale.

and $8 \%$, the data with supersaturations between 8 and $14 \%$ and the data with supersaturations between 14 and $20 \%$. Figure 5 shows the variability of IN concentration with temperature for different $S_{\mathrm{i}}$. Error bars on selected data points give some idea of the uncertainties associated with the measurement technique. This figure displays the results obtained in the present work together with the experimental data reported by Hussain and Saunders (1984), Rogers (1982), AlNaimi and Saunders (1985), Cooper (1980), and the fitting curve proposed by DeMott (2010). In order to compare these measurements with those obtained in the present work only the measurements with supersaturation below water saturation are included in Fig. 5.

The measurements of IN concentration reported by Rogers (1982) and Al-Naimi and Saunders (1985) were carried out with a continuous flow diffusion chamber at different temperatures and supersaturations, at Wyoming and Manchester, respectively. Hussain and Saunders (1984) used the same technique but only at $-16^{\circ} \mathrm{C}$ in Manchester and Cumbria. 


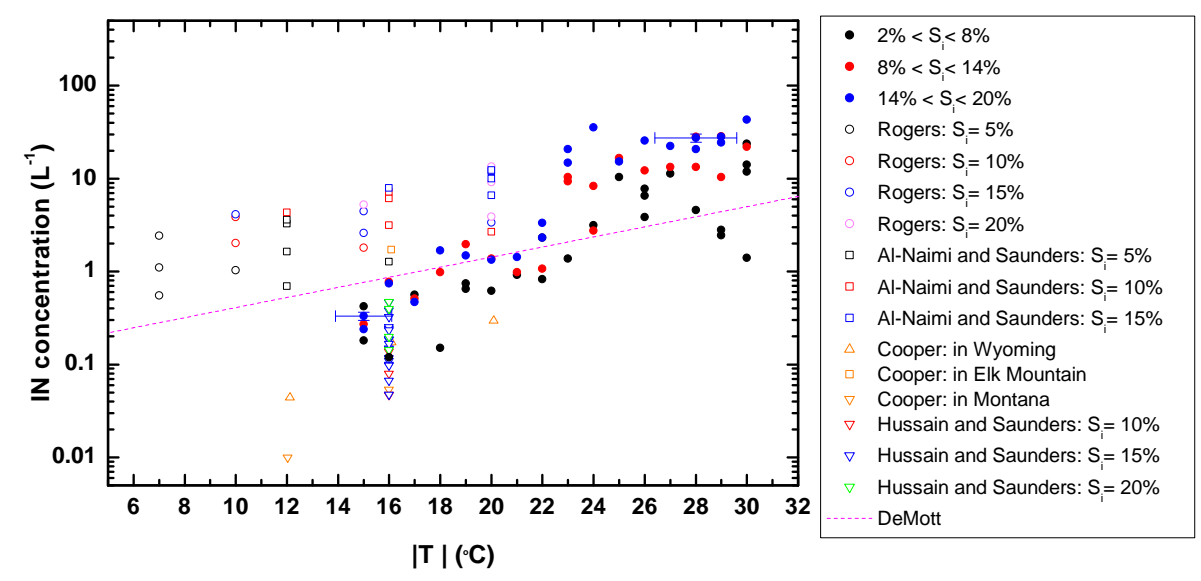

Fig. 5. Data of IN concentration vs. supercooling, for different $S_{\mathrm{i}}$. The current results and those of different authors are represented together with the fitting curve proposed by DeMott et al. (2011).

Cooper (1980) considered that IN were activated in the deposition mode at humidity of $99-100 \%$ relative to water saturation. He reported the concentration of IN at Wyoming (on the ground level and on Elk Mountain) and Montana using the method of membrane filters and a thermal diffusion processor to analyze them. The four cases are shown on the graph. The parameterization proposed by DeMott (2010) was developed from IN concentration over water saturation or above, it estimates IN concentration at all nucleation modes. This parameterization was included in the analysis for comparison because it is one of the most currently used in literature.

Figure 5 shows that the experimental data of the current work extend the temperature range used in previous measurements. In fact, there are no previous data of deposition IN for $T<-20^{\circ} \mathrm{C}$. It is possible to observe that the IN concentrations for temperatures between $-15^{\circ} \mathrm{C}$ and $-20^{\circ} \mathrm{C}$ are consistent with those previously reported by other authors; and for temperatures between $-20^{\circ} \mathrm{C}$ and $-30^{\circ} \mathrm{C}$ the experimental points behave with the same trend observed at higher temperatures.

All the experimental results, including the present one, show the tendency of the IN concentration to increase with increasing $S_{\mathrm{i}}$. In order to analize the behavior of IN concentration with $S_{\mathrm{i}}$, the data were grouped for three different temperatures, the data with temperatures between $-15^{\circ} \mathrm{C}$ and $-20^{\circ} \mathrm{C}$, the data with temperatures between $-20^{\circ} \mathrm{C}$ and $-25^{\circ} \mathrm{C}$ and the data with temperatures between $-25^{\circ} \mathrm{C}$ and $-30^{\circ} \mathrm{C}$. Figure 6 shows the variability of IN concentration with $S_{\mathrm{i}}$ for different temperatures. Again, the error bars on selected data points show the uncertainties associated with the measurement technique. This figure displays the results obtained in the present work together with the experimental data reported by Rogers (1982), Al-Naimi and Saunders (1985) and Hussain and Saunders (1984). The fitting curve of the data from Rogers (1982) and Al-Naimi and Saunders (1985) are drawn for better clarity. The results from different authors confirm that for each temperature range, the concentration of IN increases at higher supersaturation. The vertical lines indicate the saturation over liquid water at different temperatures.

Although Figs. 5 and 6 show significant scatter of the experimental data, it is important to note that the experiments have been performed with different experimental techniques; also, there are inherent spatial and temporal variations in the concentration of aerosols acting as IN, due to variations in the aerosol sources (Hoose and Möler, 2012). Regarding the seasonal variability of aerosols in Córdoba City, it is important to mention that the current measurements have been carried out during 4 months of 2012. Andrada et al. (2008) reported the seasonal variability of aerosols in Córdoba by using the Aerosol Optical Depth parameter (AOD) at 340 nanometers. AODs at different wavelength have been monitored by AERONET (AErosol RObotic NETwork) which is a federated international network coordinated by the NASA Goddard Space Flight Center (for detailed description of the acquisition instruments and data procedure see Holben et al., 1998). Even the AERONET site is $20 \mathrm{~km}$ away from Córdoba City, Andrada et al. (2008) showed the regional character of the aerosols in Córdoba. Data reported between 1999 and 2010 show that the daily averages of AOD at $340 \mathrm{~nm}$ are $0.11,0.18,0.20$ and 0.18 during Autumn, Winter, Spring and Summer, respectively (http://aeronet.gsfc.nasa. gov). Also, statistical analysis showed that the daily AOD at $340 \mathrm{~nm}$ are significantly different among the seasons. This confirms the variability of aerosol characteristics throughout the year and, therefore, the need for extending the analysis of the IN concentration for a whole year.

The temporal variations in the concentration of aerosols acting as IN during the measurement period was analyzed. Figure 7 shows the number concentration of IN as a function of the Julian day for different ranges of temperatures and supersaturations. Again, the data were grouped for three 


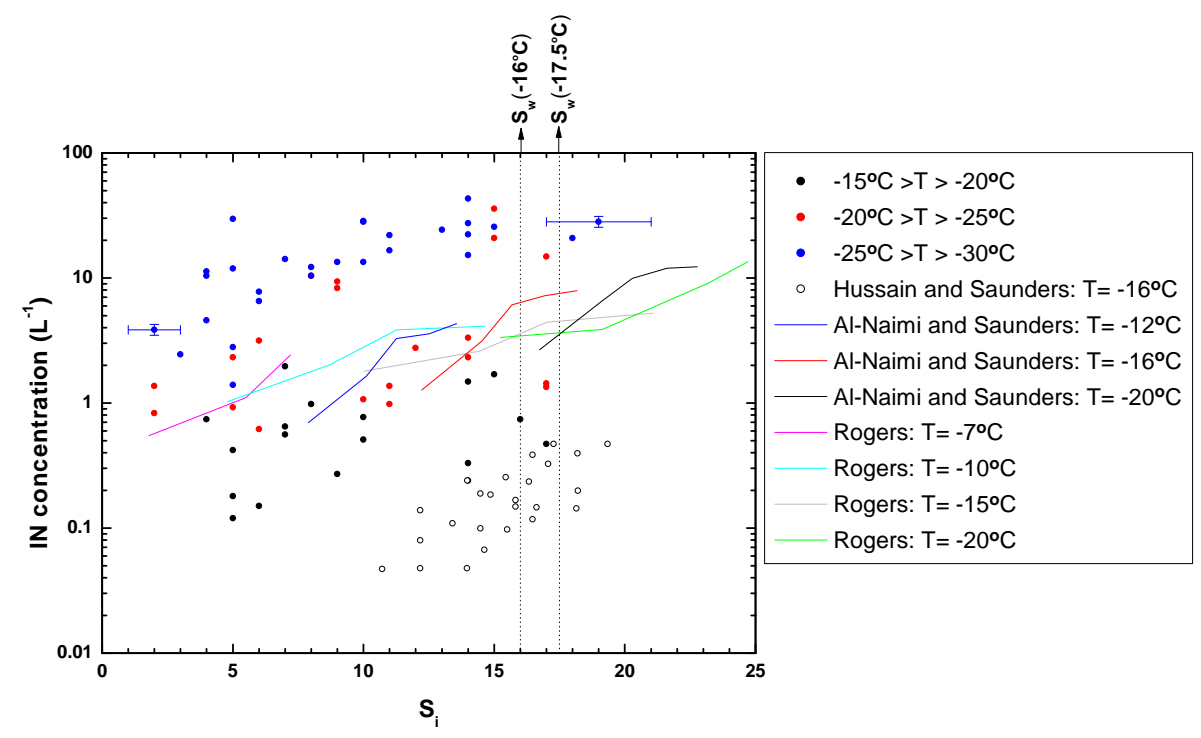

Fig. 6. Data of IN concentration vs. $S_{\mathrm{i}}$, for different temperatures. The present results and those of different authors are represented. Dotted lines indicate the water saturation at different temperatures.

different temperature ranges, the data with temperatures between $-15^{\circ} \mathrm{C}$ and $-20^{\circ} \mathrm{C}$, the data with temperatures between $-20^{\circ} \mathrm{C}$ and $-25^{\circ} \mathrm{C}$ and the data with temperatures between $-25^{\circ} \mathrm{C}$ and $-30^{\circ} \mathrm{C}$. Figure $7 \mathrm{a}$ and $\mathrm{b}$ display the results for supersaturation ranges of $[2,8] \%$ and $[8,14] \%$, respectively. Although it is not possible to perform a reliable statistical test, the results do not seem to show evidence of any particular trend during this period. However, it is important to note that the period is short to display any indication of the seasonal variability.

Elemental composition of the aerosols in Córdoba City has been reported in López et al. (2011). Anthropogenic sources have been shown to be the main responsible of the particulate matter minor than $2.5 \mu \mathrm{m}$ in aerodynamic diameter, while elements with crustal origin are increased in the particulate matter minor than $10 \mu \mathrm{m}$ in aerodynamic diameter. The variability in the chemical composition of aerosols regarding the size of the particulate matter shows the need to relate IN concentration to size and chemical composition of aerosols.

The activity of a particle as an ice nucleus depends on the temperature, supersaturation and particle characteristics. Fletcher (1962) proposed that the IN number per liter of air $(X)$ can be parameterized as a function of the temperature as:

$X=A e^{\beta \Delta T}$

where $\beta=0.6^{\circ} \mathrm{C}^{-1}, A=10^{-5} L^{-1}$ and $\Delta T=T_{1}-T, T$ is the air temperature and $T_{1} \approx-20^{\circ} \mathrm{C}$. It was found that the parameter $\beta$ varies from about 0.3 to $0.8\left({ }^{\circ} \mathrm{C}\right)^{-1}$ (Pruppacher and Klett, 1997; Levin and Cotton, 2009). On the other hand, Meyers et al. (1992) suggested that the more realistic parameterization of $X$ as a function of the supersaturation for tem-

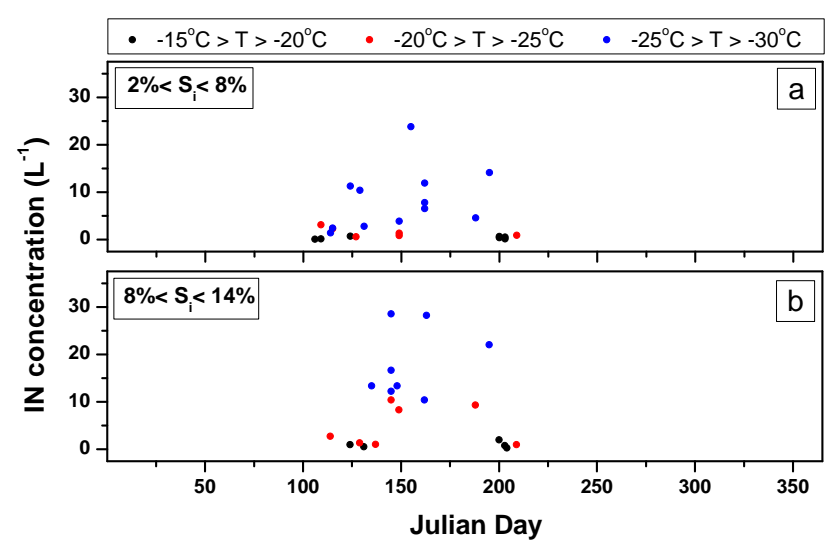

Fig. 7. Temporal evolution of the IN concentration for different temperature range and $S_{\mathrm{i}}$ ranges of (a) $[2,8] \%$ and (b) $[8,14] \%$.

peratures between -7 to $-20^{\circ} \mathrm{C}$ and supersaturation between 2 to $25 \%$ is:

$X=\exp \left(a^{\prime}+b^{\prime} S_{\mathrm{i}}\right)$

with $a^{\prime}=-0.639$ and $b^{\prime}=0.1296$, this parameterization was performed by using data reported by Rogers (1982) and AlNaimi and Saunders (1985). Thus, based on these parameterizations we propose a combination of Eqs. (1) and (2) to parameterize the results obtained in the current work. Then we use the equation:

$X=C \exp \left(a|T|+b S_{\mathrm{i}}\right)$

where $C, a$ and $b$ are constants and $T$ and $S_{\mathrm{i}}$ are in ${ }^{\circ} \mathrm{C}$ and $\%$, respectively. The best fitting corresponds to the values: 


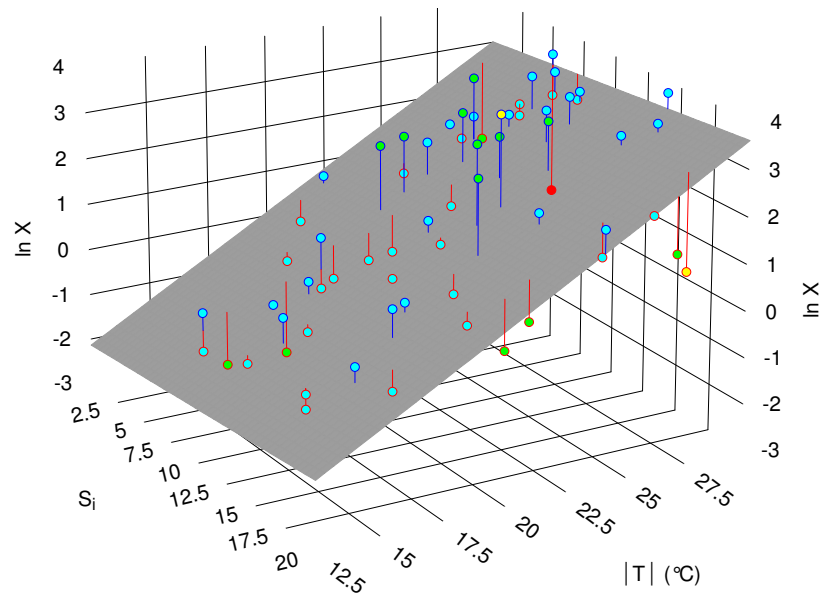

Fig. 8. Fitting of the IN concentration as a function of temperature and supersaturation given by Eq. (3), with the experimental data points superimposed. See text for details.

$C=0.0016, a=0.29^{\circ} \mathrm{C}^{-1}$, and $b=0.104$; being the square of the correlation coefficient equal to 0.79 . Figure 8 shows the data points with the fitting function superimposed. The $\ln X$ is represented in the vertical axis and $T$ and $S_{\mathrm{i}}$ on the horizontal axis. The cyan color points correspond to those within one standard deviation $(\sigma)$ of the expected value; the green points are within $2 \sigma$; the yellow points are within $3 \sigma$ and the red points are at $>3 \sigma$. The blue and red bars indicate that the points are above and below the expected values, respectively. It is possible to observe that this fit is reasonably good and may be a good representation for the current data. Also the coefficients accompanying the variables $(a$ and $b$ ) are in good agreement with previous studies $\left(\beta\right.$ and $\left.b^{\prime}\right)$.

\section{Summary and conclusion}

Studies of heterogeneous ice nucleation with natural aerosols under a broad range of thermodynamic conditions are needed in order to transfer laboratory results into parameterizations for numerical models of clouds and climate.

In this work we describe an experimental device to measure the concentration of natural ice nuclei and report laboratory experiments to determine the IN concentration as a function of temperature and supersaturation, for the temperature range $[-15,-30]^{\circ} \mathrm{C}$ and supersaturation range $[2,20] \%$ over ice. The experiments were all performed for a supersaturated-atmosphere with respect to ice and subsaturated with respect to liquid water; then, only the deposition ice nuclei were quantified in the current work.

The experimental data extend the temperature range used in previous measurements and the analysis of the results has shown that the IN concentration increases with increasing $S_{\mathrm{i}}$ and decreasing temperature. A simple functional representation of the experimental results is proposed. Thus the IN concentration is parameterized as an exponential function of the temperature and supersaturation (Eq. 3).

The current measuring system presents some advantages over the diffusion chamber method; for instance: the IN are activated and measured in times of the order of minutes, much lower temperatures can be achieved in the cloud chamber and the bulk of the aerosol sample are subjected to a fairly uniform supersaturation and temperature.

The IN measurements were conducted in an urban region placed in Córdoba, Argentina; we hope to continue this study by covering rural areas and other sites in South America.

Acknowledgements. This work was supported by Secretaría de Ciencia y Tecnología de la Universidad Nacional de Córdoba, Consejo Nacional de Investigaciones Científicas y Tecnológicas (CONICET), and Agencia Nacional de Promoción Científica (FONCYT). We want to thank Jose Barcelona for his technical assistance.

Edited by: M. Petters

\section{References}

Al-Naimi, R. and Saunders, C. P. R.: Measurements of natural deposition and condensation-freezing ice nuclei with a continuous flow chamber, Atmos. Environ., 19, 1871-1882, 1985.

Andrada, G. C., Palancar, G. G. and Toselli, B. M.: Using the optical properties of aerosols from the AERONET database to calculate surface solar UV-B irradiance in Córdoba, Argentina: Comparison with measurements, Atmos. Environ., 42, 6011-6019, 2008.

Bigg, E. K.: A new technique for counting ice-forming nuclei in aerosols, Tellus, 9, 394-400, 1957.

Bundke, U., Nilliius, B., Jaenicke, R., Wetter, T., Klein, H., and Bingemer, H.: The fast Ice Nucleus chamber FINCH, Atmos. Res., 90, 180-186, 2008.

Cantrell, W. and Heymsfield, A.: Production of ice in tropospheric clouds: A review, B. Am. Meteor. Soc., 86, 795-807, 2005.

Castro, A., Marcos, J. L., Dessens, J., Sánchez, J. L., and Fraile, R.: Concentration of ice nuclei in continental and maritime air masses in León, Spain, Atmos. Res., 47-48, 155-167, 1998.

Cooper, W. A.: A method of detecting contact ice nuclei using filter samples. 8th Intl. Conf. on Cloud Physics, Clermont-Ferrand, France, 665-668, 1980.

Curry, J. A. and Webster, P. J.: Thermodynamics of Atmospheres and Oceans, Academic Press, 1999.

DeMott, P. J.: New Directions: Need for defining the numbers and sources of biological aerosols acting as ice nuclei, Atmos. Environ., 44, 1944-1945, 2010.

DeMott, P. J., Sassen, K., Poellot, M. R., Baumgardner, D., Rogers, D. C., Brooks, S. D., Prenni, A. J., and Kreidenweis, S. M.: African dust aerosols as atmospheric ice nuclei, Geophys. Res. Lett., 30, 1732, doi:10.1029/2003GL017410, 2003.

DeMott, P. J., Möler, O., Stetzer, O., Vali, G., Levin, Z., Petters, M. D., Murakami, M., Leisner, T., Bundke, U., Klein, H., Kanji, Z. A., Cotton, R., Jones, H., Benz, S., Brinkmann, M., Rzesanke, D., Saathoff, H., Nicolet, M., Saito, A., Nillius, B., Bingemer, H., Abbatt, J., Ardon, K., Ganor, E., Georgakopoulos, D. G., and 
Saunders, C.: Resurgence in ice nuclei measurement research, B. Am. Meteor. Soc., 92, 1623-1635, 2011.

Eidhammer, T., DeMott, P. J., Prenni, A. J., Petters, M. D., Twohy, C. H., Rogers, D. C., Stith, J., Heymsfield, A., Wang, Z., Pratt, K. A., Prather, K. A., Murphy, S. M., Seinfeld, J. H., Subramanian, R., and Kreidenweis, S. M.: Ice Initiation by Aerosol Particles: Measured and Predicted Ice Nuclei Concentrations versus Measured Ice Crystal Concentrations in an Orographic Wave Cloud, J. Atmos. Sci., 67, 2417-2436, 2010.

Fletcher, N. H.: The Physics of Rain Clouds, Cambridge Univ. Press., Cambridge, UK, 1962.

Hallett, J. and Mossop, S. C.: Production of secondary ice particles during the riming process, Nature, 249, 26-28, 1974.

Hobbs, P. V. and Farber, R.: Fragmentation of ice particles in clouds, J. Res. Atmos., 6, 245-258, 1972.

Hobbs, P. V. and Rangno, A. L.: Ice particle concentrations in clouds, J. Atmos. Sci., 42, 2523-2549, 1985.

Holben, B. N., Eck, T. F., Slutsker, I., Tanré, D., Buis, J. P., Setzer, A., Vermote, E., Reagan, J. A., Kaufman, Y., Nakajima, T., Lavenu, F., Jankowiak, I., and Smirnov, A.: AERONET-A federated instrument network and data archive for aerosol characterization, Remote Sens. Environ., 66, 1-16, 1998.

Hoose, C. and Möhler, O.: Heterogeneous ice nucleation on atmospheric aerosols: a review of results from laboratory experiments, Atmos. Chem. Phys., 12, 9817-9854, doi:10.5194/acp-12-98172012, 2012.

Huffman, P. J.: Supersaturation spectra of AgI and natural ice nuclei, J. Appl. Meteor., 12, 1080-1087, 1973.

Hussain, K. and Saunders, C. P. R.: Ice nucleus measurement with a continuous flow chamber, Q. J. R. Meteorol. Soc., 110, 75-84, 1984.

Kanitz, T., Seifert, P., Ansmann, A., Engelmann, R., Althausen, D., Casiccia, C., and Rohwer, E. G.: Contrasting the impact of aerosols at northern and southern midlatitudes on heterogeneous ice formation, Geophys. Res. Lett., 38, L17802, doi:10.1029/2011GL048532, 2011.

Kulkarni, G., Fan, J., Comstock, J. M., Liu, X., and Ovchinnikov, M.: Laboratory measurements and model sensitivity studies of dust deposition ice nucleation, Atmos. Chem. Phys., 12, 72957308, doi:10.5194/acp-12-7295-2012, 2012.
Levin, Z. and Cotton, W. R.: Aerosol Pollution Impact on Precipitation: A Scientific Review, Springer, 2009.

López, M. L., Ceppi, S., Palancar, G. G., Olcese, L. E., Tirao, G., and Toselli, B. M.: Elemental concentration and source identification of PM10 and PM2.5 by SR-XRF in Córdoba City, Argentina, Atmos. Environ., 45, 5450-5457, 2011.

Meyers, M. P., DeMott, P. J., and Cotton, W. R.: New primary icenucleation parameterizations in an explicit cloud model, J. Appl. Meteorol., 31, 708-721, 1992.

Möhler, O., Field, P. R., Connolly, P., Benz, S., Saathoff, H., Schnaiter, M., Wagner, R., Cotton, R., Krämer, M., Mangold, A., and Heymsfield, A. J.: Efficiency of the deposition mode ice nucleation on mineral dust particles, Atmos. Chem. Phys., 6, 30073021, doi:10.5194/acp-6-3007-2006, 2006.

Mossop, S. C.: Microphysical properties of supercooled cumulus clouds in which an ice particle multiplication process operated, Q. J. Roy. Meteorol. Soc., 111, 183-198, 1985.

Phillips, V. T. J., DeMott, P. J., and Andronache, C.: An empirical parameterization of heterogeneous ice nucleation for multiple chemical species of aerosol, J. Atmos. Sci., 65, 2757-2783, 2008.

Pruppacher, H. R. and Klett, J. D.: Microphysics of Clouds and Precipitation, Atmospheric and Oceanographic Sciences Library, Kluwer Academic Publishers, Dordrecht, the Netherlands, 1997.

Rogers, D. C.: Field and laboratory atudies of ice nucleation in winter orographic clouds, Ph.D. dissertation, Dept. of Atmospheric Science, Univ. of Wyoming, Laramie, 161 pp., 1982.

Santachiara, G., Di Matteo, L., Prodi, F., and Belosi, F.: Atmospheric particles acting as Ice Forming Nuclei in different size ranges, Atmos. Res., 96, 266-272, 2010.

Schaefer, V. J.: The production of clouds containing supercooled water droplets or ice crystals under laboratory conditions, Bull. Amer. Soc., 29, 175, 1948.

Vali, G.: Nucleation Terminology, J. Aerosol S., 16, 575-576, 1985. 